\title{
Persistence of acute coronavirus disease 2019 infection: A rare case report
}

\author{
Anup Kumar Das', Rajnish Kumar ${ }^{2}$ \\ From ${ }^{1}$ Professor, ${ }^{2}$ Senior Resident, Department of Medicine, Assam Medical College, Dibrugarh, Assam, India
}

\begin{abstract}
In late December 2019, the outbreak of coronavirus disease 2019 (COVID-19) caused by a novel coronavirus started in Wuhan, China, and has quickly spread globally. Clinical manifestations of COVID-19 have been shown to vary widely, from asymptomatic to acute respiratory distress syndrome, cardiovascular complications, and neurological symptoms such as acute inflammatory demyelinating polyneuropathy, gastrointestinal symptoms such as progression of compensated chronic liver disease to decompensated chronic liver disease. Here, we present the case of a 60-year-old symptomatic male who was tested COVID-19 positive on rapid antigen test (RAT) and reverse transcription polymerase chain reaction (RT-PCR). The patient was given treatment as per protocol. The patient's symptoms improved gradually but his RT-PCR and RAT were persistently positive till the $40^{\text {th }}$ day of his hospital stay.
\end{abstract}

Key words: Delayed clearance, Novel coronavirus infection, Persistent coronavirus disease 2019 infection

$\mathrm{S}$ evere acute respiratory syndrome coronavirus 2 (SARS-CoV-2) belongs to the beta subgrouping of the Coronaviridae family and is an enveloped virus containing a positive-sense, single-stranded ribonucleic acid (RNA) with 29,881 bases of size [1,2]. The genome encodes for 29 proteins involved in the infection, replication, and virion assembly process. Like other coronaviruses, they are characterized by the presence of crown-like spikes on their surface [3]. The spike S protein from SARS-CoV-2 contains a receptor-binding domain that binds the human angiotensin-converting enzyme 2 (ACE 2) and thereby, promotes membrane fusion and uptake of the virus into human cells by endocytosis $[4,5]$.

\section{CASE REPORT}

A 60-year-old male patient presented with complaints of fever $\left(99^{\circ} \mathrm{F}\right)$, dry cough, and breathing difficulty for 3 days. The patient was a known diabetic for 13 years and hypertensive for 10 years with cardiomyopathy.

At presentation, the patient was conscious, oriented with a blood pressure of $140 / 90 \mathrm{~mm} \mathrm{Hg}$, pulse rate of $110 / \mathrm{min}$, respiratory rate of $28 / \mathrm{min}, \mathrm{SpO}_{2}$ of $81 \%$ on room air, and the presence of bilateral crepitations in the chest on auscultation.

A rapid antigen test (RAT) was done and it came out positive. The patient was immediately admitted in coronavirus disease 2019 (COVID-19) ICU wards and oxygen supplementation with

\section{Access this article online}

Received - 02 November 2020

Initial Review - 21 November 2020

Accepted - 23 December 2020

DOI: $10.32677 /$ IJCR.2020.v06.i12.004 a face mask was started. Oxygen saturation improved to $88 \%$ and later on, he was put on a face mask with a reservoir and was maintained at oxygen saturation of $95-96 \%$ at high flow oxygen at (10 L/Min).

Inj. Methylprednisolone $250 \mathrm{mg}$ OD, inj. Low molecular weight heparin 60mg s.c OD., and inj. Remdesivir along inj. Piperacillin tazobactam $4.5 \mathrm{~g}$ i.v tds were started (as per the state protocol). On further evaluation, the patient gave a history of dyspnea on exertion and breathing difficulty on lying down for 1 year. In his previous echocardiography reports, the left ventricular ejection fraction was 33\%. Cardiology consultation was taken and tab. Ramipril $2.5 \mathrm{mg}$ OD, tab. Furosemide $20 \mathrm{mg}$ OD, tab. Aldactone 25mg OD, and a beta-blocker were started. Routine investigations are shown in Table 1.

On the $9^{\text {th }}$ day, the RAT was repeated and the patient was again tested positive. The patient was stable till the $10^{\text {th }}$ day of admission when he complained of severe breathing difficulty with a sudden fall in oxygen saturation to $75 \%$ on a face mask with reservoir. The patient was put on non-invasive ventilation and was started inj. alteplase $25 \mathrm{mg}$ in $100 \mathrm{ml} \mathrm{NS}$ over $1 \mathrm{~h}$ followed by $25 \mathrm{mg}$ in $100 \mathrm{ml}$ NS over $12 \mathrm{~h}$ followed by tab. Dabigatran $110 \mathrm{mg}$ BD. The patient was maintaining oxygen saturation of $95-96 \%$ on non-invasive ventilation. RAT was repeated every $3^{\text {rd }}$ day which repeatedly came out positive. Due to repeated positivity of RAT, Tab. Sofosbuvir (400 mg) and Daclatasvir (60 mg) OD were started for 14 days on day 18 of the hospital stay.

Gradually, the patient's condition improved and was again put on a face mask with reservoir and later on, a face mask with high

\footnotetext{
Correspondence to: Dr. Rajnish Kumar, Senior Resident, Department of Medicine, Assam Medical College, Dibrugarh, Assam, India. E-mail: rajsurgeon1989@gmail.com

(C) 2020 Creative Commons Attribution-NonCommercial 4.0 International License (CC BY-NC-ND 4.0).
} 
flow oxygen was maintained at oxygen saturation of $95-96 \%$. After completing sofosbuvir and daclatasvir, the patient's condition improved day by day but his RAT was repeatedly coming out positive till the $40^{\text {th }}$ day of his hospital. His reverse transcription-polymerase chain reaction was also repeated on the $20^{\text {th }}$ day which came out to be positive with a cycle threshold (CT) value of 14 . The patient was finally tested negative on rapid antigen on the $42^{\text {nd }}$ day of his hospital stay.

Table 1: Laboratory value of routine blood test

\begin{tabular}{lc}
\hline Laboratory parameters & Value \\
\hline Hemoglobin & $12.3 \mathrm{~g}$ \\
Total count & 13,700 \\
Differential leukocyte count & $\mathrm{N}=94, \mathrm{~L}=04, \mathrm{M}=01, \mathrm{E}=01, \mathrm{~B}=0$ \\
Platelet count & 1.8 lakh \\
Prothrombin time & $16.20 \mathrm{~s}$ \\
INR & 1.2 \\
Urea & 43.30 \\
Creatinine & 0.88 \\
D-dimer & 2.17 \\
S. ferritin & $>1000$ \\
CRP & $>9$ \\
Procalcitonin & $0.13 \mathrm{ng}$ \\
Random blood glucose & $330 \mathrm{mg} \%$ \\
Total protein & $5.24 \mathrm{~g}$ \\
Albumin & $3.0 \mathrm{~g}$ \\
Total bilirubin & $1.76 \mathrm{~g}$ \\
Direct bilirubin & $0.32 \mathrm{~g}$ \\
Indirect bilirubin & $1.44 \mathrm{~g}$ \\
Alanine aminotransferase & 50 \\
Aspartate aminotransferase & 30 \\
Alkaline phosphatase & 45 \\
Gamma glutamyl transferase & 37 \\
Sodium & 128 \\
Potassium & 4.10 \\
\hline CR: C-reave \\
(n)
\end{tabular}

CRP: C-reactive protein

\section{DISCUSSION}

SARS-COV-2 is emerging as a multisystem infectious disease. The various studies have shown the different time of clearance of the virus after acute infection for asymptomatic and symptomatic patients. The factors associated with delayed viral clearance are age $>60$ years and $<18$ years [6], chest tightness on presentation [7], use of glucocorticoids, hepatitis $\mathrm{C}$, and immunocompromised state (human immunodeficiency virus) [8].

The incubation period of COVID-19 is 5-6 days but can be up to 14 days. The host receptor for viral entry into the cell ACE-2 is highly expressed in adult nasal epithelial cells. The virus undergoes local replication and propagation into the respiratory tract and manifests with symptoms of fever, malaise, and dry cough. There is an immune response during this phase (Stage 1 of Fig. 1). The majority of the patients do not progress beyond this phase as the mounted immune response is sufficient to contain the spread of infection. About one-fifth of all infected patients involve the lower respiratory tract and the virus invades the type 2 alveolar epithelial cells through ACE-2 receptor and starts to undergo replication to produce more viral nucleocapsid and produce the symptoms of pneumonia and dyspnea (Stage 2 of Fig. 1). The virus-laden pneumocyte now release many different cytokines and inflammatory markers such as interleukins (ILs) (IL-1, IL-6, and IL-8), tumor necrosis factor-alpha, interferon-gamma, and interferon-beta. This cytokine storm is responsible for subsequent inflammation and lung injury which manifest as acute respiratory distress syndrome and respiratory failure (Stage 3 of Fig. 1). The recent studies have shown that the median time to viral clearance was found to be 30 days from diagnosis and 36 days from symptom onset, with a trend that increased with increasing age and that was slightly longer in hospitalized patients, suggesting that clearance was slower in the more severe cases [9].

According to information from the United States Centers for Disease Control and Prevention, by 3 days after clinical recovery, if viral RNA is still detectable in the upper respiratory specimens, the RNA concentrations are generally at or below

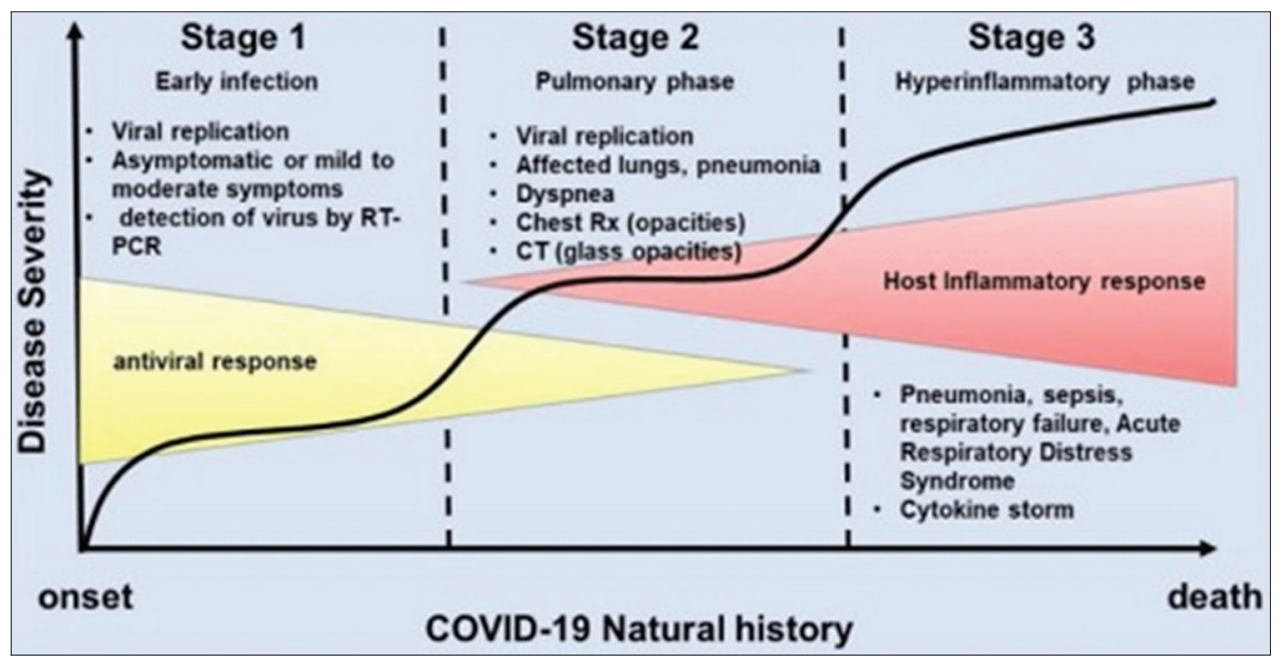

Figure 1: Natural history of acute coronavirus disease 2019 infection 
the levels at which replication-competent virus can be reliably isolated; additionally, isolation of infectious virus from the upper respiratory specimens more than 10 days after illness onset has only rarely been documented in patients who had a non-severe infection and whose symptoms have resolved $[10,11]$. Contrary to this, we observed a CT of 14 on the $20^{\text {th }}$ day which indicates high viral load and infectivity.

The studies done by Kim et al. has shown that $86.7 \%$ of the 120 included subjects achieved viral clearance within 37 days of follow-up but that ten subjects $(8.3 \%)$ were still positive by day 40. This study also observes an increase in time to viral clearance with greater disease severity, with increasing age, and in the absence of antiviral therapy [12]. A recent case report states that viral shedding was detected up to 49 days from symptom onset [13]. In a study by Zhang et al., it has been shown that the virus clearance rates within $1,2,3,4,5$, and 6 weeks were $1.5 \%, 36.6 \%, 73.4 \%, 90.2 \%, 97.3 \%$, and $100 \%$, respectively. The virus clearance rates of the mild to moderate cases were $1.5 \%, 45 \%, 83.9 \%, 96.9 \%, 100 \%$, and $100 \%$, respectively. The virus clearance rates of the severe cases were $1.5 \%, 20 \%, 52.3 \%$, $76.9 \%, 92.3 \%$, and $100 \%$, respectively. Within 2,3 , 4, and 5 weeks, the viral clearance rate of severe patients was less than that of the non-severe patients [6]. We started tablet sofosbuvir and daclatasvir to hasten the clearance of the virus which has been proved to shorten the viral clearance and hospital stay in some studies $[14,15]$.

\section{CONCLUSION}

Out of more than 2000 COVID-19 patients admitted in our hospital, we report an unusual presentation of this case, where the infection was persistent for 40 days. Our patient also had diabetes mellitus, hypertension, and cardiomyopathy which may influence viral clearance by immunodepression and needs consideration. The important aspect of this reporting is that this category of patients' needs special attention for policymakers because in a resource-poor country such patients cannot be kept for a longer duration in the hospital neither these can be sent for home isolation as the period of infectivity is still not known which needs large scale clinical trials.

\section{REFERENCES}

1. Lu R, Zhao X, Li J, Niu P, Yang B, Wu H, et al. Genomic characterisation and epidemiology of 2019 novel Coronavirus: Implications for virus origins and receptor binding. Lancet 2020;395:565-74.

2. Chen L, Liu W, Zhang Q, Xu K, Ye G, Wu W, et al. RNA based mNGS approach identifies a novel human Coronavirus from two individual pneumonia cases in 2019 Wuhan outbreak. Emerg Microbes Infect 2020;9:313-9.

3. Schoeman D, Fielding BC. Coronavirus envelope protein: Current knowledge. Virol J 2019;16:69.

4. Verity R, Okell LC, Dorigatti I, Winskill P, Whittaker C, Imai N, et al. Estimates of the severity of Coronavirus disease 2019: A model-based analysis. Lancet Infect Dis 2020;20:669-77.

5. Gralinski LE, Menachery VD. Return of the Coronavirus: 2019-nCoV. Viruses 2020;12:135.

6. Zhang L, Yang X, Li X, Jia Y, Huang F, Zhang K, et al. Influencing Factors of Virus Duration and Virus Clearance in COVID-19 Patients in Shenzhen: A Retrospective study, Research Square; 2020.

7. $\mathrm{Hu} X$, Xing Y, Jia J, Ni W, Liang J, Zhao D, et al. Factors associated with negative conversion of viral RNA in patients hospitalized with COVID-19. Sci Total Environ 2020;728:138812.

8. Zhao J, Liao X, Wang H, Wei L, Xing M, Liu L, et al. Early virus clearance and delayed antibody response in a case of Coronavirus disease 2019 (COVID-19) With a history of coinfection with human immunodeficiency virus Type 1 and Hepatitis $C$ virus. Clin Infect Dis 2020;71:2233-5.

9. Mancuso P, Venturelli F, Vicentini M, Perilli C, Larosa E, Bisaccia E, et al. Temporal profile and determinants of viral shedding and of viral clearance confirmation on nasopharyngeal swabs from SARS-CoV-2-positive subjects: A populationbased prospective cohort study in Reggio Emilia, Italy. BMJ Open 2020;10:e040380.

10. Centers for Disease Control and Prevention. Symptom-Based Strategy to Discontinue Isolation for Persons with COVID-19: Decision Memo; 2020. Available from: https://www.cdc.gov/coronavirus/2019-ncov/community/ strategy-discontinue-isolation.html. [Last accessed on $2020 \mathrm{Jul}$ 04].

11. Liu WD, Chang SY, Wang JT, Tsai MJ, Hung CC, Hsu CL, et al. Prolonged virus shedding even after seroconversion in a patient with COVID-19. J Infect 2020;81:318-56.

12. Kim H, Hong H, Yoon SH. Diagnostic performance of CT and reverse transcriptase polymerase chain reaction for Coronavirus disease 2019: A meta-analysis. Radiology 2020;296:E145-55.

13. Tan L, Kang X, Zhang B, Zheng S, Liu B, Yu T, et al. A Special Case of COVID-19 with Long Duration of Viral Shedding for 49 Days, medRxiv; 2020.

14. Elfiky AA, Mahdy SM, Elshemey WM. Quantitative structure-activity relationship and molecular docking revealed a potency of anti-Hepatitis C virus drugs against human Corona viruses. J Med Virol 2017;89:1040-7.

15. Wentzel A. Sofosbuvir and Daclatasvir for the Treatment of COVID-19: Results from a Randomised Controlled Trial, IAS COIVD-19 Conference; 2020. Available from: https://www.cattendee.abstractsonline.com/ meeting/9307/presentation/3933. [Last accessed on 2020 Oct 25].

Funding: None; Conflicts of Interest: None Stated.

How to cite this article: Das AK, Kumar R. Persistence of acute coronavirus disease 2019 infection: A rare case report. Indian J Case Reports. 2020;6(12):685-687. 